\title{
CUIDADO Y SELECCIÓN DE LAS VOCACIONES SACERDOTALES
}

DOI: https://doi.org/10.52039/seminarios.v62i218.110

GUALTIERO SIGISMONDI*

\section{INTRODUCCIÓN}

Toda reforma verdadera en la Iglesia comienza por su interior, por los presbíteros y los consagrados, y en consecuencia pasa por los seminarios. Hasta qué punto es esto cierto lo subrayó Hubert Jedin en un artículo publicado en 1963 en la revista Seminarium, titulado «La importancia del decreto tridentino sobre los seminarios en la vida de la Iglesia». Este gran historiador del concilio de Trento observa que «la crisis del cisma fue, en última instancia, la crisis de la formación sacerdotal». En su opinión, con el decreto Cum adolescentium aetas -aprobado por unanimidad en la Sesión XXIII, 15 de julio de 1563-, que imponía a cada diócesis la apertura de un seminario para cuidar las vocaciones al sacerdocio ordenado, la Iglesia ha recorrido un largo camino durante el cual ha tenido que actualizar varias veces el modelo de formación del clero y acomodarlo a las exigencias de los contextos en continuo cambio. Sin entrar en la historia de los documentos magisteriales que, a partir del decreto conciliar Optatam totius, ofrecen el horizonte normativo de las propuestas y las dinámicas de aprendizaje del seminario, vamos a fijarnos en los factores que, en las circunstancias actuales, interpelan a una institución tan venerable como venerada, necesitada de una renovación profunda y, sobre todo, de un discernimiento más riguroso a la hora de seleccionar a los formadores.

\section{LA «SOLIDEZ» DE LOS FORMADORES}

«La calidad del Presbiterio de una Iglesia particular depende en buena parte de la del seminario, y, por esta razón, de la calidad de los responsables de la formación». Esta observación -realizada por Benedicto XVI el 19 agosto de 2005 en Colonia, en el discurso dirigido a los seminaristas con motivo de la XX Jornada Mundial de la Juventud- evidencia que una inversión insuficiente, incluso desde el punto de vista cuantitativo, en la selección e incorporación

\footnotetext{
* Gualtiero Sigismondi es obispo de Foligno (Italia).
} 
de educadores para un seminario constituye una grave amenaza para la vida de la Iglesia. Entre las primeras responsabilidades del obispo está la de poner al frente del seminario sacerdotes capaces de un discernimiento riguroso y exigente, comprometidos a tiempo pleno en llevar a cabo la obra de arte del acompañamiento, que consiste, como afirma el papa Francisco en la exhortación apostólica Evangelii gaudium, 169, en «quitarse las sandalias, porque estás en la tierra sagrada del otro» (Ex 3,5$)$, para proteger y hacer crecer las vocaciones, que «son un diamante en bruto que trabajar con cuidado, para hacerlos brillar en medio del pueblo de Dios». El arte del acompañamiento, que no tolera ni el paternalismo ni la permisividad, es un trabajo artesanal, sinodal, fruto de la habilidad, la paciencia, la transparencia, así como de una gran confianza en la obra de la gracia; la única autoridad permitida es la del testimonio y el único enfoque posible es caminar al lado.

El primer paso del declive de un seminario se da con el debilitamiento del equipo docente, pero la campana de alarma suena cuando el director espiritual se ve obligado a ir de un lado a otro, porque está sobrecargado de tareas pastorales. Sus «apariciones» no son lo suficientemente frecuentes como para que pueda comprobar con sus propios ojos si cuanto le confían al oído está dicho desde la sinceridad del corazón. Así, se limita a realizar alguna intervención de "primeros auxilios», sin incidir de modo decisivo en la vida de cada uno y de la comunidad. El «paliativo» o el «sedante» del director espiritual «a tiempo parcial» proporciona a los seminaristas la coartada para buscar fuera de la comunidad educativa modelos de referencia, los cuales a menudo cumplen la función de tutores, y a veces también de confesores. Si bien el director espiritual no se identifica con el confesor habitual, su presencia estable facilita a los seminaristas la disposición a abrir sus almas, lo cual es más delicado que la misma acusación de los pecados. Por tanto, la stabilitas que connota la figura del director espiritual no puede ser delegada ni en el rector ni en los demás educadores -elegidos con cuidado entre los sacerdotes jóvenes, a menudo acreditados, además de como formadores, como animadores-, la mayoría de los cuales soportan el peso y la fatiga de «involucrarse sin dejarse llevar», o sea, sin perder el "carácter asimétrico» de una relación educativa, que siempre debe conjugar libertad y disciplina, porque la libertad responsable, iluminada por la fe, es la mejor defensa de la misma disciplina.

La escasez crónica de formadores, que hasta las diócesis más grandes padecen, sugiere como oportuna y cada vez más actual la erección de seminarios regionales o inter-diocesanos -como sucedió al comienzo del siglo $\mathrm{XX}$ en diversas regiones de Italia-, que son la "piedra de toque» del camino sinodal de las Iglesias particulares de una misma región metropolitana o eclesiástica. La experiencia enseña que no basta con unificar las fuerzas en los institutos teológicos de las diócesis más cercanas, principalmente porque 
esta solución obliga a los seminaristas a andar de un lado para otro, como viajeros, y también porque los expone a restar tiempo a la oración y al estudio. La dimensión diocesana aparece irrenunciable para los seminarios menores, cuyo desmantelamiento o supresión -allí donde ha ocurrido- ha supuesto un duro golpe para la "cadena» de la pastoral vocacional y ha dejado un vacío educativo paliado sólo en parte por la implantación de grupos vocacionales de adolescentes -grupos, quizás, a la sombra del campanario de la parroquia- o de grupos propedéuticos integrados por jóvenes que, tras haber terminado sus estudios universitarios o -cada vez con más frecuencia- haber estado algunos años trabajando, se inclinan por entrar en el seminario.

\section{LA «PUERTA ESTRECHA» DE LA ETAPA PROPEDÉUTICA}

Después de un largo periodo de ajuste que, desgraciadamente, ha incluido una fase de "rebajas», la etapa propedéutica ${ }^{1}$ se ha configurado como un tiempo dirigido no tanto a llenar los vacíos en la cultura humanística de base como a iniciar una intensa experiencia de seguimiento de Cristo, sin confundir conversión a la vida cristiana con vocación al sacerdocio. Entre una y otra no hay, de hecho, una relación causa-efecto: la conversión se dirige al redescubrimiento de la consagración bautismal y no al descubrimiento de lo que la lex orandi llama «semillas de vocación que Dios siembra a manos llenas en el campo de la Iglesia». La conversión opera una «renovación del modo de pensar, para poder discernir la voluntad de Dios» (Rom 12, 2): prepara un terreno humano idóneo para adentrarse en la escucha de las Escrituras; inaugura la confrontación con la pregunta que Jesús planteó a los dos discípulos de Juan Bautista: «¿Qué buscáis?» (Jn 1, 38).

El periodo propedéutico se puede comparar con una "puerta estrecha» que hay que cruzar no para romper con el pasado, sino para madurar. No es como una "zona franca» por la que conviene pasar a toda prisa, sino como una «zona de tráfico restringido» que recorrer a «pie descalzo», no sólo para "entrar en los entresijos y en las heridas de lo vivido», sino también para conectar las virtudes teologales con las cardinales, y para poner en equilibrio el corazón y la mente, la razón y el sentimiento, el cuerpo y el espíritu. El periodo propedéutico sirve para madurar la conciencia de que la elección vocacional sólo puede darse dentro de un auténtico crecimiento en la fe, dejando emerger tanto la pregunta que dio inicio al camino de conversión de Saulo: «¿Quién eres, Señor?», como la pregunta, subordinada a la primera, que marcó el punto de partida de su vocación misionera: «¿Qué debo hacer,

1. A este respecto, el 1 de mayo de 1998 la Congregación para la Educación católica publicó un documento titulado La etapa propedéutica. 
Señor?» (Hch 22, 8.10). La experiencia de Saulo, que fue guiado hasta Damasco por sus compañeros y visitado después por Ananías (Hch 22, 11-16), enseña que todo camino vocacional es un diálogo entre Dios y la persona moderado por el discernimiento de la Iglesia.

Este momento inicial del discernimiento, «en el que se vive la belleza de la llamada en la fase que se podría definir de enamoramiento ${ }^{2}$, es ciertamente el más favorable para dar un espacio adecuado a las ciencias psicopedagógicas, teniendo en cuenta la «diferencia sustancial y no sólo de grado» entre las dos instancias, necesarias entre sí, del foro interno: el camino de la dirección espiritual y el recorrido psicológico. Si por un lado no es comprensible un rechazo por prejuicios de la contribución que la psicología ofrece, por otro no es aceptable firmarle un cheque en blanco. La exigencia de encontrar un punto de equilibrio entre estos dos extremos se ha hecho más fuerte por el notable aumento de aspirantes al presbiterado que, como señala el papa Francisco, «llevan en su vida la experiencia de la propia familia herida, con ausencia de padres y con inestabilidad emotiva» (Amoris laetitia, 203). Al proceder de contextos familiares frágiles -lo cual contribuye a prolongar la adolescencia y a debilitar la identidad afectiva-, estos necesitan una pedagogía que les permita adquirir, sin escrúpulos ni ligereza, la libertad de no dejarse dominar por sus limitaciones, la rectitud de intención y la consistencia de las motivaciones que subyacen en la primera inclinación por seguir a Jesús. El sensible aumento de familias heridas, en un contexto social ya de por sí «líquido», hace que cada vez con mayor frecuencia pidan entrar en el seminario muchachos con una identidad sexual no claramente definida. La Congregación para la Educación católica, en su Instrucción del 4 de noviembre de 2005, recuerda sin eufemismos que «la Iglesia no puede admitir al seminario ni a las órdenes sagradas a quienes practican la homosexualidad, presentan tendencias homosexuales profundamente arraigadas o defienden la llamada cultura gay».

«No se puede llenar los seminarios -advierte el papa Francisco-con cualquier tipo de motivaciones, y menos si estas se relacionan con inseguridades afectivas, búsquedas de formas de poder, glorias humanas o bienestar económico» (Evangelii gaudium, 107). Se trata de un tema muy presente en el corazón del Santo Padre, el cual ha llamado muchas veces la atención de los obispos sobre la necesidad de que los criterios para formar y seleccionar las vocaciones sacerdotales estén muy bien definidos. «Nosotros obispos -lamenta el papa Francisco- tenemos la tentación de admitir sin discernimiento a los jóvenes que se presentan. Esto es un mal para la Iglesia. Es necesario estudiar bien el recorrido de una vocación: examinar bien si es del Señor, si es un hombre sano, si es equilibrado, si es capaz de dar vida, de evangelizar, de formar una familia y de renunciar a esta para seguir a Jesús. Hoy tenemos

2. Benedicto XVI, Carta a los seminaristas, 18 de octubre de 2010. 
muchos problemas en muchas diócesis por los errores de algunos obispos al haber admitido a cualquiera que venía a veces expulsado de otros seminarios o de casas religiosas. Debemos pensar en el bien del pueblo de Dios ${ }^{3}$. Ésta es precisamente la suprema lex: la salus animarum, que se inspira en una Instrucción de la Congregación para la Educación católica, del 8 de marzo de 1996, cuyas disposiciones están vigentes y de gran actualidad para evitar al pueblo de Dios daños irreparables, a menudo dejados como herencia por pastores inclinados a la acogida más allá de lo razonable y lícito.

Impresiona la intervención «fuera de programa» que hizo el Papa en el Consistorio ordinario celebrado los días 12 y 13 de febrero de 2015. Poniendo en evidencia que algunos obispos «poco conscientes y vigilantes» reciben alumnos que han sido expulsados de otros seminarios o institutos religiosos, el Santo Padre subrayó que se trata de una irresponsabilidad, afirmando textualmente: «Por favor, poned fin a esta tendencia y dejad de meter lobos rapaces en vuestra grey». Se trata de palabras muy claras y fuertes que no dejan lugar a interpretaciones ni a excepciones. A este respecto, puede ser útil recordar, a modo de ejemplo, el Decreto general sobre la admisión al seminario de candidatos procedentes de otros seminarios o de familias religiosas -aprobado por la XLV Asamblea general de la CEI y promulgado el 27 de marzo de 1999-, en el cual se determina que «no pueden ser tomadas en consideración las peticiones de admisión de aquellos que, después de los dieciocho años de edad, han dejado por segunda vez el seminario o instituto, o han sido expulsados del mismo».

\section{EL «TIEMPO FUERTE» DEL SEMINARIO MAYOR}

La admisión en el seminario no abre un «tiempo suplementario» en el camino propedéutico, sino que inaugura un «tiempo fuerte» de silencio interior, de oración constante, de estudio asiduo y de «prudente inserción en las acciones y estructuras pastorales de la Iglesia». El seminario, por tanto, más que un «espacio» es un «tiempo». "El espacio -escribe el papa Franciscocristaliza los procesos, el tiempo proyecta a su vez hacia el futuro y anima a caminar con esperanza» (Lumen fidei, 57). Y aún más, el seminario mayor, colocado entre el yunque del calendario académico y el martillo de las experiencias pastorales, está cada vez más expuesto al riesgo de «fragmentar el tiempo transformándolo en espacio». Las actividades pastorales en las que participan los seminaristas cada fin de semana y que se prolongan en la subsiguiente implicación emocional, difuminan el «tiempo fuerte» del seminario, reduciéndolo a un internado que no favorece el crecimiento y el desarrollo de

3. Discurso en la Plenaria de la Congregación para el Clero, 3 de octubre de 2014. 
las actitudes propias de la vida comunitaria: la acogida recíproca, la apertura al diálogo, la espontaneidad y la gratuidad en los gestos concretos de servicio, la sinceridad y la libertad en las amistades, la atención a las pequeñas cosas y a la gestión del tiempo.

Toda semilla de vocación madura en el campo de la vida comunitaria, labrado mediante la corrección fraterna, que forma para «soportarse mutuamente con amor» (Ef 4, 2), «perdonarse unos a otros» (Col 3, 13) y «competir en el amor recíproco» (Rom 12, 10). «La formación tiene su humus en la comunidad y en la vida cotidiana». En el proyecto formativo de un seminario no hay, en efecto, prueba más selectiva que la vida en común, puesto que la insuficiente capacidad para relacionarse-dependencia exclusiva, desconfianza obsesiva, complicidad posesiva - y la falta de pasión apostólica apuntan a la carencia vocacional. La preparación al rito de admisión entre los candidatos al diaconado y al presbiterado es el momento oportuno para podar las ramas que no portan fruto, que no dejan pasar la savia de la vida fraterna, sino que se sienten atraídas por la «mundanidad virtual que se nos pone delante con la facilidad de un simple clic». Es oportuno preguntarse, a fin de suscitar la reflexión y el debate, si no habrá llegado el momento de introducir, tras el bienio filosófico, un periodo de clarificación y poda fuera del seminario, aunque siempre dentro de una experiencia comunitaria de tipo caritativo o de missio ad gentes.

La disciplina de la vida fraterna educa para establecer vínculos de amistad sincera, la que alegra la casa de Betania, y para mantener una constante tensión armónica entre soledad y comunión, orientando a los seminaristas a tomar conciencia de que «el sacerdocio ministerial es vocación a la pertenencia al presbiterio unido en torno al obispo», y a reconocer en el celibato «no tanto un don en función del ministerio, sino una especial conformación al estilo de vida del mismo Cristo». Para discernir si un seminarista está preparado - ¡no es suficiente con que esté dispuesto!- para vivir el celibato, necesitamos verificar si es capaz de vigilar sus fragilidades y de testimoniar, con madurez, alegría y dedicación, que el Señor basta para llenar su corazón. Si es verdad que el corazón late allí donde se encuentra su tesoro (Mt 6, 21), lo es igualmente que el corazón sigue a los ojos (Job 31,7) y que «la lámpara del cuerpo es el ojo» (Mt 6, 22). La contaminación del corazón e incluso de la mente depende de la mirada, y su sanación está ligada a su luminosidad. ¿Hacia dónde se inclina el corazón? Esta es la pregunta de fondo que articula el «tiempo fuerte» del seminario, una etapa cargada de promesas en la que se aprende el arte de tener «fijos los ojos en Jesús» (Heb 12, 2), cultivando la lectio divina y la adoración eucarística. Por un lado, la escucha orante de la Palabra, rumiada en el silencio, ayuda a hacer la transición del texto bíblico a la vida, reduciendo la brecha entre espiritualidad y vida cotidiana. Por otro, el «asombro eucarístico» madura la creencia de que «el cuidado de la vida interior es la primera actividad pastoral, la más importante». 
La prueba de fuego del proyecto educativo de un seminario es la intensidad de la vida de oración, cultivada en el espíritu de la liturgia. Esta no tolera la nostalgia de ciertas formas transitorias que en vano apelan a la tradición, ni soporta el descuido que se evidencia en un no siempre adecuado discernimiento de la calidad de ciertos cantos y melodías utilizados en las celebraciones, que parecen no valorar el patrimonio de la música sacra o la universalidad del canto gregoriano. Reducidas las tensiones sobre la pertenencia de los seminaristas a varias asociaciones católicas y/o a diversos grupos o movimientos eclesiales, las cuales parecen tener una significación menor ahora respecto a un pasado no muy remoto, los educadores se encuentran con que tienen que afrontar la delicada tarea de apagar los brotes de contraste entre ideologías «tradicionalistas» y «progresistas» que cada vez más encuentran en el seminario un espacio de incubación que condiciona, entre otros, la búsqueda de armonía entre doctrina y pastoral.

La historia enseña que la doctrina no se puede desconectar de la pastoral: no se trata de adecuar la doctrina a la pastoral, sino de no arrebatar a la doctrina su sello pastoral originario y constitutivo. Los primeros síntomas de la desconexión entre pastoral y doctrina se advierten ya en el seminario, cuando no se sabe conectar oración y estudio, que necesitan ambos silencio, escucha y atención. Si la inquietud de la mente no deja aquietar el corazón, es inevitable caer en la dicotomía que divide la esfera racional y el mundo afectivo; en esto son mayormente hostigados los seminaristas más «brillantes», inclinados a olvidar, por un lado, que el camino seminarístico no coincide con el currículum de los estudios teológicos y, por otro, que la ordenación sacerdotal manifiesta «la audacia de Dios» en descubrir dentro del corazón de una creatura humana la imagen de Cristo, «sumo y eterno Sacerdote», sin garantizar que será mejor que los otros ni, mucho menos, impedir que pueda ceder o caer.

\section{EL «ESCRUTINIO» DEL SEXTO AÑO}

Si es verdad que la vida concreta en el ministerio con sus pruebas, sus fatigas y sus alegrías constituye el cumplimiento permanente del proceso formativo básico, lo es asimismo que «la incertidumbre de la formación inicial muestra la fragilidad de la respuesta vocacional». Es difícil leer y comprender ciertos estilos de la vida de los presbíteros sin remontarse a los años de la formación inicial, a la calidad del proceso educativo, a los criterios para la admisión en el seminario y para la evaluación de la idoneidad de la estructura humana y psicológica de los candidatos al diaconado y al presbiterado. La necesaria continuidad entre la fase inicial y la permanente de la formación de los presbíteros sugiere que hay que prestar mayor atención al «sexto año», erróneamente concebido como una especie de «botadura» en la que el seminarista sale del «astillero» del seminario mayor y cae en las «aguas» 
de la vida pastoral. Se trata de una etapa en cierto modo semejante a la de la construcción de un barco, que tiene como fin crear la circularidad entre teoría y praxis, entre fe creída y fe vivida, que están recíprocamente unidas. Desgraciadamente, el frenesí del «cuidado de la urgencia por la urgencia del cuidado" hace poco incisivo el sexto año, reducido a un atajo que da acceso inmediato a la vida pastoral o, al contrario, a cursos de especialización. Así como la salida del seminario a la parroquia provoca cada vez con más frecuencia graves tensiones y dudas, es necesario preguntarse qué significa, en las actuales circunstancias, lo que Pablo recomienda a Timoteo: «No tengas prisa en imponer las manos a alguien, para no hacerte cómplice de los pecados de otros» (1 Tim 5, 23).

Aun siendo una praxis consolidada conferir la ordenación diaconal al inicio del sexto año, conviene preguntarse si sería bueno esperar hasta el final del mismo. Se trata, en efecto, de una experiencia que tiene la función de verificar la actitud no sólo para la caridad, sino también para el estilo sinodal. Y, una vez superado, se ha de comprobar si los candidatos al diaconado y al presbiterado han realizado no sólo un generoso desprendimiento de cosas y afectos, sino también una concreta renuncia a sí mismo, sin la cual, con el tiempo, se corre el riesgo de «volver atrás» (Lc 9, 57-62) y pretender cobrar incluso los «intereses» de cuanto presumen haber invertido, presentando la cuenta -iel saldo!- de la melancolía o incluso de la tristeza. El sexto año representa, pues, un paso delicado que permite verificar si se está aprendiendo a no guardar para sí la propia vida (Mt 10,39), a vivir la obediencia «sin sombra de ficción», sin «caricaturas» quizás esbozadas ya en los años de seminario:

-obediencia simulada: se dice sí, pero se entiende no;

-obediencia ostentosa: se dice sí para ser admirado;

-obediencia resentida: se dice sí con la boca chica, apretando los dientes;

-obediencia tarifada: se dice sí poniendo el veto del pero o del excepto;

-obediencia resignada: se dice sí por inercia;

-obediencia pactada: se dice sí por un tiempo determinado;

-obediencia medida: se dice sí sin entonar el magníficat.

Invertir sin darse es un estado en el que se encuentran los que, en los años de seminario, aprietan los dientes sin abrir el corazón, se pasan la vida dejándose llevar por la costumbre, entre hipocresía y superficialidad. Se trata de trastornos sutiles que, si se convierten en crónicos, causan algunas de las patologías diagnosticadas por el cardenal Juan Bautista Montini en la carta que dirigió a los sacerdotes ambrosianos en la Semana Santa de 1959: «El cálculo del mínimo esfuerzo, el arte de evitar el aburrimiento, el sueño de una soledad dulce y tranquila, la excusa de la propia timidez, la incapacidad sostenida por la pereza, la defensa de lo obligatorio y nada más, los horarios protectores de la propia comodidad y no la de los otros». 
La formación de los presbíteros, teniendo como horizonte último el pueblo de Dios, está orientada a hacer crecer auténticos «hombres de Iglesia», dignidad que es típica de quienes «ven en el propio ministerio sólo el cumplimiento de la voluntad de Dios y el servicio desinteresado a la Iglesia». «El testimonio de un sacerdocio bien vivido -recomendaba Benedicto XVI- ennoblece a la Iglesia, suscita admiración en los fieles, es fuente de bendición para la comunidad, es la mejor promoción vocacional» ${ }^{4}$. El nacimiento de la vocación es, pues, el primer fruto de un presbiterio en el que los sacerdotes viven en comunión entre sí y en una Iglesia comprometida hasta el fondo con la nueva evangelización. No podemos hacernos la ilusión de que estamos formando «verdaderos presbíteros»-«incansables en el don de sí, vigilantes en la plegaria, alegres y acogedores en el servicio a la comunidad»- si no procuramos hacer crecer «hombres íntegros». Esta aguda observación, que el seminarista Primo Mazzolari anota en su Diario, anticipa la confidencia que él mismo, siendo ya párroco, hará a un joven sacerdote que le expone sus dificultades espirituales y pastorales: «Tú estás viendo la tierra en otoño, cuando acaba de ser sembrada y donde por el momento nada germina; yo, en cambio, la estoy viendo ya en febrero, cuando los campos comienzan a vestirse de verde y anuncian el perfume de la primavera».

\section{CONCLUSIÓN}

Si el seminario, como se suele pensar, es una creación del concilio de Trento, es necesario preguntarse si será capaz de superar indemne la confrontación con las cambiantes exigencias de los tiempos. Hace cinco siglos, el seminario era literalmente un "vivero» al que se le confiaban muchachos -poco más que niños, y por tanto con una personalidad aún no estructurada- para que los instruyera, seleccionara y eventualmente formara para la vida sacerdotal: como en un auténtico "semillero», a la siembra le seguía el desbroce, la extirpación de las plantas brotadas de semillas extrañas y el trasplante al campo. Hoy, sin embargo, el ingreso en el seminario se produce en un contexto muy distinto: con una frecuencia cada vez mayor, quien solicita entrar tiene una personalidad marcada por múltiples experiencias no siempre favorales y de las cuales, en ocasiones, está huyendo; a menudo ha tenido relaciones afectivas y experiencias profesionales más o menos satisfactorias; a veces ha terminado una carrera universitaria y, debido a cómo está estructurado el seminario, se ve de nuevo sentado en un pupitre y rodeado de un ambiente que le parece más propio de un aula de enseñanza secundaria que

4. Benedicto XVI, Discurso a los sacerdotes, a las personas de vida consagrada y a los seminaristas, reunidos en Aparecida el 12 de mayo de 2007, con ocasión de la V Conferencia general del Episcopado Latinoamericano y del Caribe. 
de un centro de estudios universitarios. La sensación es que recibe una formación de algún modo incompleta e insuficiente, que no le llega al corazón, que prepara para ser funcionarios del culto, pero que no siempre consigue afectar y transformar la sensibilidad.

El individualismo que existe entre los sacerdotes exige la reforma de la institución del seminario, que tiene necesidad de ir acompañada -ciertamente no sustituida- por otras experiencias formativas que tengan en cuenta, con el necesario realismo, las mudables condiciones en las que se encuentra al actuar. La solución de complementar en el seminario, al menos en algunos periodos, con comunidades más pequeñas, que el obispo confía a presbíteros de probada experiencia, es una frontera a explorar.

Algunas preguntas que conviene plantear y responder en esta nueva situación son: ¿Qué recorridos ofrecer a los candidatos al sacerdocio que, en virtud de las edades y las experiencias vividas, no pueden seguir un itinerario formativo experimentado en el joven seminarista? ¿Cómo guiar a los jóvenes hasta hace poco no cercanos (o convertidos) a la fe a reflexionar sobre una eventual llamada a la vida sacerdotal o consagrada? ¿Cómo discernir en eventuales aspirantes seminaristas perfiles problemáticos ligados a la huida por fracasos afectivos o profesionales, e incluso al deseo de encontrar estabilidad económica y valorarles tras periodos difíciles? ¿Cómo descubrir antes de la admisión a las órdenes sagradas, un razonable tiempo de reflexión que permita verificar la idoneidad para seguir el camino iniciado, para que el Señor lo lleve a cumplimiento? ¿Cómo garantizar una prudente inserción en la vida pastoral que permita al pueblo cristiano contribuir al juicio de idoneidad del que el obispo tiene absoluta necesidad para proceder a la ordenación? ¿Cómo promover la presencia de las familias en la formación sacerdotal para ofrecer a los seminaristas la posibilidad de apreciar la variedad y complementariedad de las diversas vocaciones?

Sin duda, puede ser útil comenzar a dialogar con estos interrogantes para suscitar la búsqueda de una respuesta $\mathrm{o}$, al menos, de una orientación compartida. 